\title{
Luminescence studies on swift heavy ion irradiated nanocrystalline aluminum oxide
}

\author{
K.R. Nagabhushana ${ }^{\text {a,b }}$, B.N. Lakshminarasappa ${ }^{\text {a,* }}$, D. Revannasiddaiah ${ }^{c}$, Fouran Singh ${ }^{\text {d }}$ \\ ${ }^{a}$ Department of Physics, Jnanabharathi, Bangalore University, Bangalore 560 056, India \\ ${ }^{\mathrm{b}}$ Department of Science and Humanities, P.E.S. Institute of Technology, 100 Feet Ring Road, Banashankari III stage, Bangalore 560 085, India \\ ${ }^{\mathrm{c}}$ Department of Studies in Physics, University of Mysore, Manasa Gangotri Campus, Mysore 570 006, India \\ ${ }^{\mathrm{d}}$ Inter University Accelerator Centre, Post Box No. 10502, Aruna Asaf Ali Marg, New Delhi 110 067, India
}

\section{A R T I C L E I N F O}

\section{Article history:}

Received 31 March 2008

Received in revised form

10 November 2010

Accepted 26 November 2010

Available online 2 December 2010

Keywords:

Nanocrystalline $\mathrm{Al}_{2} \mathrm{O}_{3}$

Swift heavy ions

Photoluminescence

Thermoluminescence

\begin{abstract}
A B S T R A C T
Pellets of nanocrystalline aluminum oxide synthesized by a combustion technique are irradiated with $120 \mathrm{MeV} \mathrm{Au}^{9+}$ ions for fluence in the range $5 \times 10^{11}-1 \times 10^{13}$ ions $\mathrm{cm}^{-2}$. Two photoluminescence (PL) emissions, a prominent one with peak at $\sim 525 \mathrm{~nm}$ and a shoulder at $\sim 465 \mathrm{~nm}$ are observed in heat treated and $\mathrm{Au}^{9+}$ ion irradiated aluminum oxide. The $525 \mathrm{~nm}$ emission is attributed to $\mathrm{F}_{2}^{2+}$-centers. The $\mathrm{PL}$ intensity at $525 \mathrm{~nm}$ is found to increase with increase in ion fluence up to $1 \times 10^{12}$ ions cm $\mathrm{cm}^{-2}$ and decreases beyond this fluence. Thermoluminescence (TL) of heat-treated and swift heavy ion (SHI) irradiated aluminum oxide gives a strong and broad TL glow with peak at $\sim 610 \mathrm{~K}$ along with a weak shoulder at $500 \mathrm{~K}$. The TL intensity is found to increase with $\mathrm{Au}^{9+}$ ion fluence up to $1 \times 10^{13}$ ions cm $\mathrm{cm}^{-2}$ and decreases beyond this fluence.
\end{abstract}

(c) 2010 Elsevier B.V. All rights reserved.

\section{Introduction}

Nanomaterials have attracted many researchers in various fields, including physics, chemistry, material science, biology and genetics [1]. They are considered to be good candidates for optoelectronic applications. There are distinct advantages and issues of using nanoscale phosphors for lighting, displays and related applications. Phosphor nanoparticles and nanostructured films have obvious advantages for greater spatial resolution in high definition displays [2]. Another promising application of nanostructured materials is similar to phosphors in field emission displays [3]. These flat-panel displays use a cold-cathode ( $<1 \mathrm{keV})$ electron emitter tip to excite the phosphor screen. Luminescent nanostructured materials are attractive for FED applications because of their small size that allows complete penetration by the low-voltage electrons for efficient material utilization. The close proximity of the phosphor particles to the emitter tips requires that the phosphor does not outgas or sputter a material that will poison the tips and the high current excitation requires phosphors with low thermal quenching [4]. In addition to lamps and optical displays, a number of phosphor materials is used for long-persistence phosphors, thermometry $[5,6]$ and radiation dosimetry [7]. Thermoluminescence kinetics have been found to be different in nanoparticles [8], and in one report the nanoscale

\footnotetext{
* Corresponding author. Tel.: +9194481 16281; fax: +91 8023219295.

E-mail address: bnlnarasappa@gmail.co (B.N. Lakshminarasappa).
}

material did not saturate as readily as microcrystals, giving the nanomaterials a larger dynamic range [9]. The interest in nanocrystalline aluminum oxide is due to their potential applications in the fabrication of TLD phosphors and optical devices such as optical amplifiers and display phosphors in opto-electronic devices $[10,11]$. The luminescence produced in solids due to the impact of high-energy ions was recently the subject matter of investigations [12,13]. When SHI pass through a solid target, a large amount of energy is deposited due to inelastic collision with target electrons, which in turn induce new damage process. In particular, close to the ion path, extremely high energies are deposited in a very small volume of a few hundreds of $\mathrm{eV} \mathrm{nm}^{-3}$ within an extremely short time but difficult to reach by any other radiation source. The high electronic excitation density in the core region has strong influence on the defect creation [14]. Good amount of work, though not exhaustive with heavy ion beams on sapphire $[15,16]$ and polycrystalline aluminum oxide [17], has been reported. In this paper, new experimental results are presented on photoluminescence (PL) and thermoluminescence (TL) in swift heavy ion irradiated combustion synthesized nanocrystalline $\mathrm{Al}_{2} \mathrm{O}_{3}$.

\section{Experimental}

Nanocrystalline aluminum oxide is synthesized by the combustion technique based on the procedure discussed in detail elsewhere [10]. The stoichiometric amounts of redox mixture (aluminum nitrate, ammonium nitrate and glycene; Merck Chemicals, India) are 
dissolved in $100 \mathrm{ml}$ of double-distilled water in a cylindrical Pyrex dish of $300 \mathrm{ml}$ capacity. The dish containing the homogeneous mixture is introduced into a muffle furnace maintained at $400 \pm 5{ }^{\circ} \mathrm{C}$. Initially, the solution boils and undergoes dehydration followed by decomposition with evaporation of a large amount of gasses, leaving behind a powder. The final product is voluminous and nanocrystalline. To remove the carbon impurities left behind, the sample is annealed at $900{ }^{\circ} \mathrm{C}$ in a muffle furnace for $3 \mathrm{~h}$. The pellets of $\mathrm{Al}_{2} \mathrm{O}_{3}$ of $6 \mathrm{~mm}$ diameter and $1 \mathrm{~mm}$ thickness are prepared by applying a pressure of 7 tons per ram of $6 \mathrm{~mm}$ diameter, i.e. $70 \mathrm{MPa}$ using a home-made pelletizer. One of these samples is used as pristine for comparison with irradiated ones and the others are irradiated with $120 \mathrm{MeV}$ swift $\mathrm{Au}^{9+}$ ions for various fluences in the range $5 \times 10^{11}-2 \times 10^{13}$ ions $\mathrm{cm}^{-2}$ using a 15UD tandem Pelletron accelerator in the Materials Science beam line at Inter University Accelerator center, New Delhi. PL studies are performed using a He-Cd laser (KIMMON) and a Michelle 900 spectrograph in the range $200-1100 \mathrm{~nm}$. TL measurements are carried out at a heating rate $(\beta)$ of $5 \mathrm{Ks}^{-1}$ using PC based TL analyzer (Nucleonix Systems Pvt. Ltd Hyderabad, India).

\section{Results and discussion}

The structural characteristics of combustion-synthesized nanocrystalline $\mathrm{Al}_{2} \mathrm{O}_{3}$ are studied by the XRD technique. Using the Scherer formula, the average grain size of the phosphor is calculated to be $\sim 9 \mathrm{~nm}$. It may be noted that heat treatment of nanomaterials may affect the grain size. However, in the present case, $\mathrm{Al}_{2} \mathrm{O}_{3}$ heat-treated at $900{ }^{\circ} \mathrm{C}$ does not show much variation in grain size because, nanocrystalline $\mathrm{Al}_{2} \mathrm{O}_{3}$ shows gamma phase and it changes to the most stable $\alpha$-phase only above $1700{ }^{\circ} \mathrm{C}$ [18]. Based on SRIM (stopping and range of ions in solids) calculations the electronic energy loss $\left(S_{e}\right)$ and nuclear energy loss $\left(S_{n}\right)$ for $120 \mathrm{MeV}$ gold projectile ions and aluminum oxide target are calculated to be 24.8 and $0.4 \mathrm{keV} \mathrm{nm}^{-1}$, respectively. The range of $120 \mathrm{MeV}$ Au ions in $\mathrm{Al}_{2} \mathrm{O}_{3}$ is $9.1 \mu \mathrm{m}$, and can be calculated using the SRIM software developed by Ziegler [19]. The software was downloaded from www.srim.org. The luminescence response is extremely sensitive to the nature of defects and their interaction. PL is a well established, nondestructive and widely practiced tool for the identification of defects in opaque materials where optical absorption studies cannot be carried out. Therefore, PL is used as a technique to identify the ion-induced defects. PL emission $\left(\lambda_{e x}=326 \mathrm{~nm}\right)$ spectra of pristine and $120 \mathrm{MeV}$ swift $\mathrm{Au}^{9+}$ ion irradiated nanocrystalline $\mathrm{Al}_{2} \mathrm{O}_{3}$ are shown in Fig. 1. A broad and complex PL emission in the range 400-600 $\mathrm{nm}$ along with a prominent and well resolved PL emission with peak at $770 \mathrm{~nm}$ are observed in unirradiated samples. However, when the samples are irradiated with swift $\mathrm{Au}^{9+}$ ions, a prominent PL emission with a peak at $\sim 525 \mathrm{~nm}$ along with shoulder at $\sim 465 \mathrm{~nm}$ is observed. However, the characteristic $770 \mathrm{~nm}$ emission observed in irradiated samples is very weak but well resolved, as can be seen from Fig. 1. A well resolved PL emission with peak at $770 \mathrm{~nm}$ observed in unirradiated samples is attributed to $\mathrm{Ti}^{3+}$ impurities [20]. Further, after irradiation, the characteristic $770 \mathrm{~nm}$ emission was observed to be very weak, as can be seen from the Fig. 1 . As widely known, the structural changes due to SHI irradiation cause reduction in PL intensity due to defects acting as nonradiative recombination centers, whose concentration certainly increases with increasing ion fluence. A weak emission with peak at $\sim 695 \mathrm{~nm}$ is observed in all samples and is attributed to $\mathrm{Cr}^{3+}$ impurities present in the material [21].

Further, oxygen loss may not take place during $120 \mathrm{MeV} \mathrm{Au}^{9+}$ ion irradiation, as $\mathrm{Al}_{2} \mathrm{O}_{3}$ is a highly radiation-resistant material. Instead, oxygen is ionized and displaced from its site leading to anion vacancy and subsequently electrons are trapped in it to form color centers (F- and F-aggregate centers).

Al Ghamdi and Townsend [22] have reported two optical absorption bands with peaks at $355(3.49 \mathrm{eV})$ and $460 \mathrm{~nm}(2.70 \mathrm{eV})$ in He ion irradiated $\mathrm{Al}_{2} \mathrm{O}_{3}$ and they are attributed to $\mathrm{F}_{2}^{+}$and $\mathrm{F}_{2}^{2+}$ centers, respectively. PL of these centers when excited with 355 and $460 \mathrm{~nm}$ gives rise to emission with peaks at 380 and $520 \mathrm{~nm}$, respectively. They observed enhancement in PL intensity with ion fluence. The samples used in the present investigation are opaque in nature and optical absorption studies could not be carried out. However, diffuse reflectance is an excellent sampling tool for powdered materials in the mid-IR and NIR spectral ranges. In the present work, it is observed that PL intensity at $525 \mathrm{~nm}$ corresponding to $\mathrm{F}_{2}^{2+}$-center increases with increase in $\mathrm{Au}^{9+}$ ion fluence and reaches maximum up to about $1 \times 10^{12}$ ions $\mathrm{cm}^{-2}$ and then decrease with further increase in ion fluence. Dalmasso et al. [23] reported PL emission at $2.3 \mathrm{eV}(540 \mathrm{~nm})$ when polycrystalline $\mathrm{Al}_{2} \mathrm{O}_{3}$ was irradiated with 365 and $540 \mathrm{MeV} \mathrm{Kr}$ ions followed by excitation at $2.7 \mathrm{eV}$ $(460 \mathrm{~nm})$. They attributed the $2.3 \mathrm{eV}$ emission peak to $\mathrm{F}_{2}^{2+}$-centers (two oxygen vacancies with two electrons).Therefore, it is believed that $525 \mathrm{~nm}$ emission observed in the present work might be due to

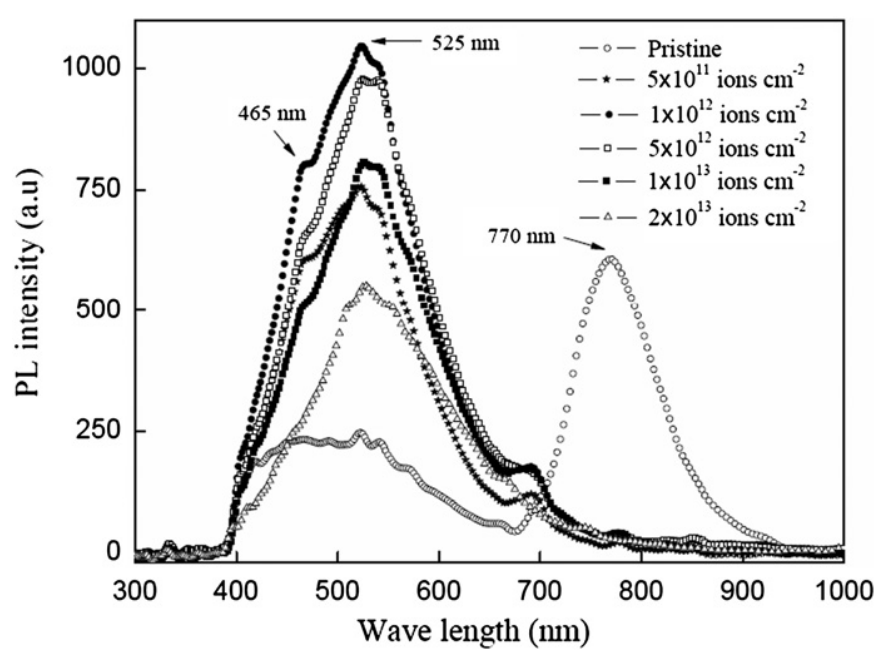

Fig. 1. PL emission ( $\lambda_{e x}=326 \mathrm{~nm}$ ) spectra of pristine and $120 \mathrm{MeV}$ swift $\mathrm{Au}^{9+}$ ion irradiated nanocrystalline $\mathrm{Al}_{2} \mathrm{O}_{3}$ heat-treated at $900{ }^{\circ} \mathrm{C}$.

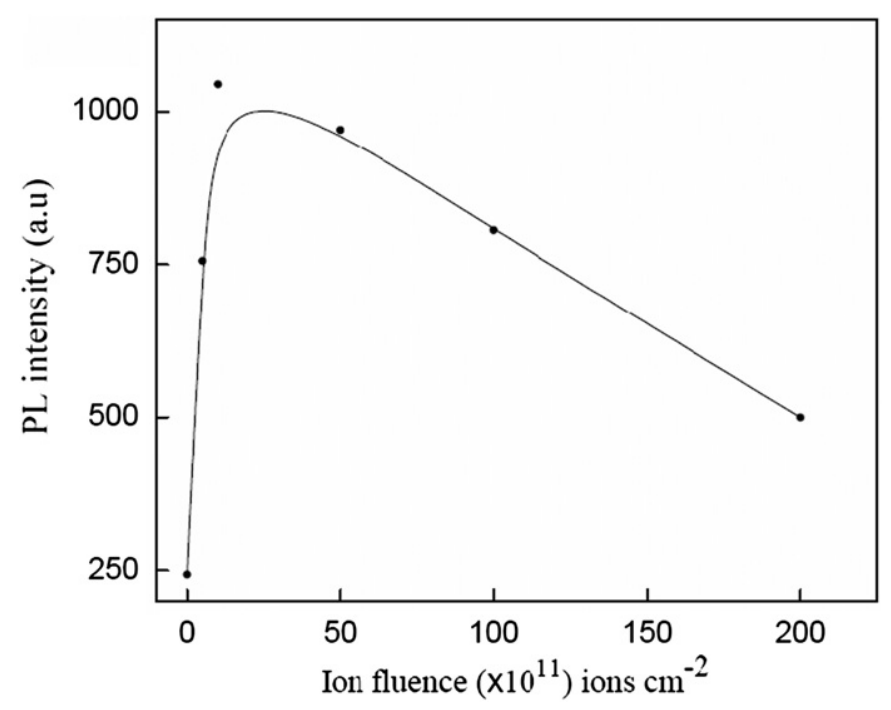

Fig. 2. Variation in PL intensity with $120 \mathrm{MeV}$ swift $\mathrm{Au}^{9+}$ ion fluence in nanocrystalline aluminum oxide. 
$\mathrm{F}_{2}^{2+}$-centers [17]. Fig. 2 shows the variation in PL intensity at $525 \mathrm{~nm}$ with $120 \mathrm{MeV}$ swift $\mathrm{Au}^{9+}$ ion fluence in nanocrystalline aluminum oxide. It is observed that, PL intensity increases with increase in ion fluence up to $1 \times 10^{12}$ ions $\mathrm{cm}^{-2}$ and thereafter it decreases with further increase in ion fluence. The increase in PL intensity might be due to increase in defect concentration $\left(\mathrm{F}_{2}^{2+}\right)$ caused by $\mathrm{Au}^{9+}$ ion irradiation. Further, increase in $\mathrm{Au}^{9+}$ fluence may annihilate the primary defects and give rise to growth of new defect centers. Hence, decrease in PL intensity in the present work may be attributed to the annihilation of primary defect centers.

Thermoluminescence is a very common and yet simple technique used for estimation of doses of high-energy ionizing radiations absorbed in materials. As-prepared $\mathrm{Al}_{2} \mathrm{O}_{3}$ i.e., pristine samples, did not show any thermoluminescence (TL) response. However, it may be noted that samples irradiated with SHI, UV, X or gamma rays show TL response. Thermoluminescence glow curves of $120 \mathrm{MeV}$ swift $\mathrm{Au}^{9+}$ ion irradiated nanocrystalline aluminum oxide annealed at $900{ }^{\circ} \mathrm{C}$ are shown in Fig. 3. A prominent and well resolved TL glow with peak at $610 \mathrm{~K}$ and a shoulder at $\sim 500 \mathrm{~K}$ is observed. Fig. 4 shows the variation in TL glow peak intensity and glow peak temperature (Tg2) with fluence in $120 \mathrm{MeV} \mathrm{Au}^{9+}$ ion irradiated nanocrystalline aluminum oxide. It is observed that, the

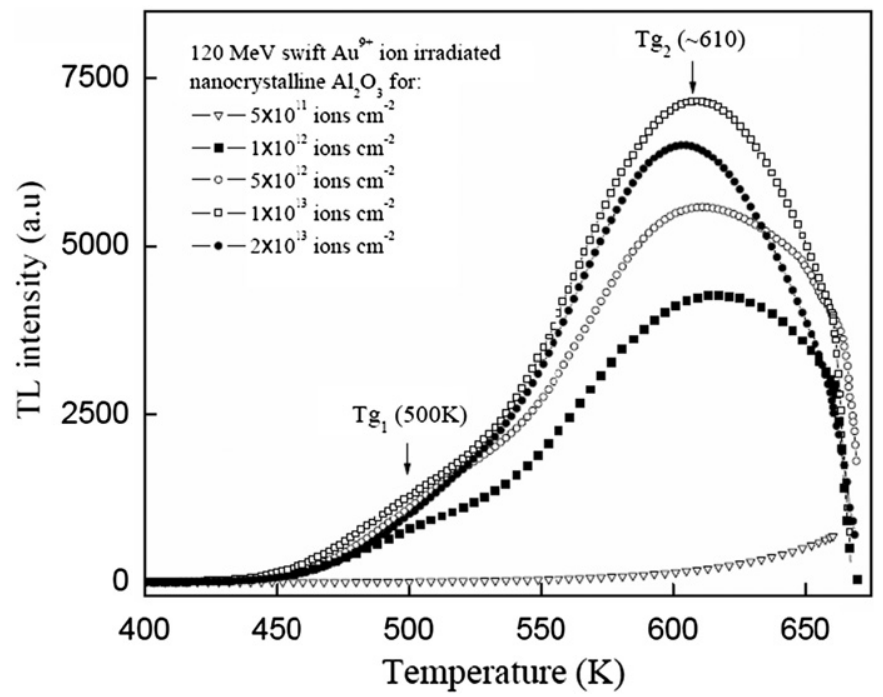

Fig. 3. Thermoluminescence glow curves of $120 \mathrm{MeV}$ swift $\mathrm{Au}^{9+}$ ion irradiated nanocrystalline aluminum oxide.

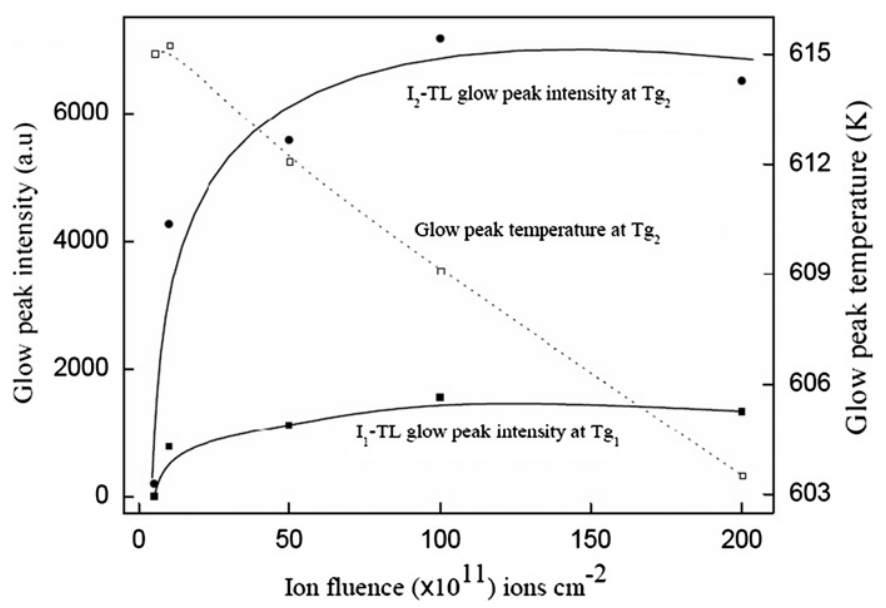

Fig. 4. Variation in TL glows peak intensity $(I)$ and glow peak temperature $(\operatorname{Tg} 2)$ with ion fluence for the data shown in Fig. 3.

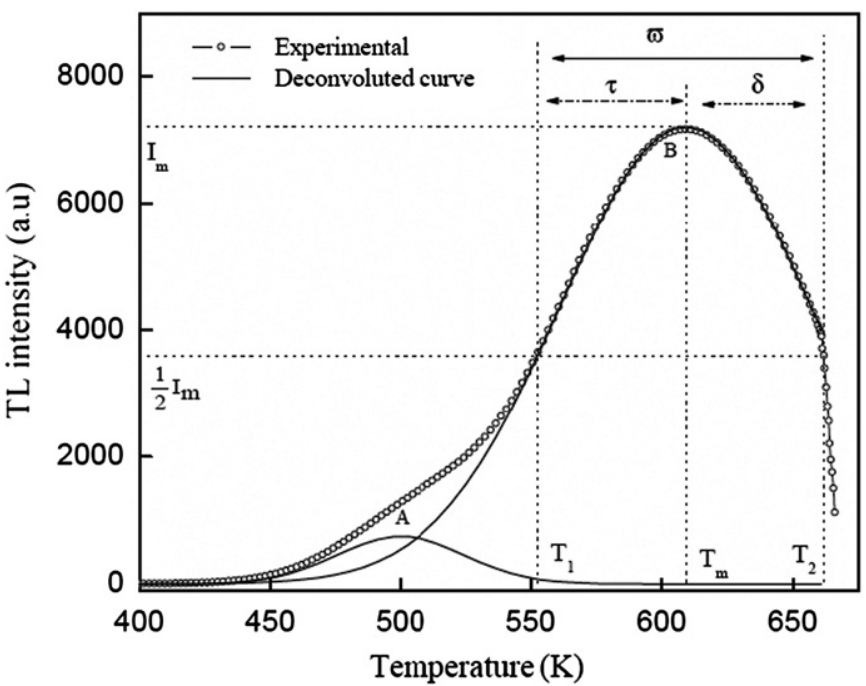

Fig. 5. Thermoluminescence deconvoluted glow curve of $120 \mathrm{MeV}$ swift $\mathrm{Au}^{9+}$ $1 \times 10^{13}$ ions $\mathrm{cm}^{-2}$ irradiated nanocrystalline aluminum oxide.

glow peak intensities at $\operatorname{Tg} 1$ and $\operatorname{Tg} 2$ increase with ion fluence up to $1 \times 10^{13}$ ions $\mathrm{cm}^{-2}$ and reaches saturation. And the TL intensity is found to decrease with further increase in ion fluence but this decrease is not significant. However, if we irradiate with fluence beyond $2 \times 10^{13}$ ions $\mathrm{cm}^{-2}$ the decrease is certainly significant. Further, it may be noted that TL intensity increases rapidly up to $1 \times 10^{12}$ ions $\mathrm{cm}^{-2}$. This may be correlated with the observed PL results. The higher temperature glow peak $(\mathrm{Tg} 2)$ in the present work is found to be shifted towards lower temperature side with increase in ion fluence.

The evaluation of kinetic parameters such as activation energy $(E)$ of the traps involved in TL emission, order of kinetics $(b)$ and frequency factor $(s)$ associated with the TL glow peaks, is one of the important aspects of studies in condensed matter physics. These parameters are estimated using glow curve shape method based on the modification by Chen et al. [24]. The detailed calculations using a set of equations are discussed elsewhere [25].

Fig. 5 shows deconvoluted glow curve of nanocrystalline aluminum oxide irradiated for the fluence of $1 \times 10^{13}$ ions $\mathrm{cm}^{-2}$. The complex glow curve is deconvoluted into two simple curves with peak at $610 \mathrm{~K}$ (named as peak B) and $502 \mathrm{~K}$ (named as peak A). Following Halperin and Braner [26], one can define a geometry factor $\mu_{\mathrm{g}}=\delta / \omega$, where $\delta$ is the high temperature half-width and $\omega$ is the full width at half-maximum (see Fig. 5). This factor would be typically 0.42 for pure first-order glow peak and 0.52 for second order glow peak. The value of $\mu_{g}$ for curve $\mathrm{A}$ is found to be 0.44 , which is closer to 0.42 . This implies that curve A (see figure) indicates the first-order kinetics, which obeys Randall-Wilkins first-order expression. $\mu_{\mathrm{g}}$ for curve $\mathrm{B}$ is found to be 0.48 , which is closer to 0.52 and it may be inferred that the glow curve $B$ exhibits intermediate kinetics. The trap parameters estimated by glow curve shape method are tabulated in Table 1.

\section{Conclusions}

Nanocrystalline aluminum oxide irradiated with $120 \mathrm{MeV} \mathrm{Au}^{9+}$ ions shows good PL and TL responses. The observed PL emission with peak at $525 \mathrm{~nm}$ is ascribed to $\mathrm{F}_{2}^{2+}$-center emission. A prominent $\mathrm{TL}$ glow with peak at $610 \mathrm{~K}$ shows intermediate kinetics. The TL glow peak intensity is found to increase with increase in ion fluence up to $1 \times 10^{13}$ ions $\mathrm{cm}^{-2}$ and then it saturates. The $610 \mathrm{~K}$ glow peak in the present studies finds its importance in dosimetric studies. 
Table 1

Kinetic parameters of nanocrystalline aluminum oxide irradiated with swift $\mathrm{Au}^{+9}$ ions, obtained using the glow curve shape method (modified by $\mathrm{Chen}$ et al. [24]).

\begin{tabular}{|c|c|c|c|c|c|c|c|c|c|}
\hline \multirow{2}{*}{$\begin{array}{l}\text { Ion fluence } \\
\text { (ions } \mathrm{cm}^{-2} \text { ) }\end{array}$} & \multirow{2}{*}{$\begin{array}{l}\text { TL glow } \\
\text { curve }\end{array}$} & \multirow[t]{2}{*}{$T_{m}(\mathrm{~K})$} & \multirow[t]{2}{*}{$\mu_{\mathrm{g}}$} & \multirow[t]{2}{*}{$b$} & \multicolumn{4}{|c|}{ Activation energy (eV) } & \multirow[t]{2}{*}{$s\left(\mathrm{~s}^{-1}\right)$} \\
\hline & & & & & $E_{\tau}$ & $E_{\delta}$ & $E_{\omega}$ & $E_{\text {ave }}$ & \\
\hline \multirow[t]{2}{*}{$1 \times 10^{13}$} & A & 502.40 & 0.44 & 1 & 0.901 & 0.951 & 0.948 & 0.933 & $4.698 \times 0^{08}$ \\
\hline & B & 609.90 & 0.48 & 2 & 0.750 & 0.864 & 0.808 & 0.807 & $0.536 \times 10^{06}$ \\
\hline
\end{tabular}

\section{Acknowledgement}

The authors express their sincere thanks to Prof. K.C. Patil, Emeritus Professor, Department of Inorganic and Physical Chemistry, Indian Institute of Science, Bangalore, India, for his constant encouragement and valuable suggestions during the preparation of samples.

\section{References}

[1] C.P. Poole Jr, F.J. Owens, Introduction to Nanotechnology, Wiley-Interscience, New Jersey, 2006.

[2] H. Yamamoto, H. Matsukiyo, J. Lumin. 48-49 (1991) 43.

[3] P.R. Schwoebel, I. Brodie, J. Vac. Sci. Technol. B 13 (1995) 1391.

[4] S. Itoh, Phosphors for full color low voltage FEDs, Ext. Abs., in: Proceedings of the 3rd International Conference on the Science and Technology of Display Phosphors, Huntington Beach, CA, November 1997.

[5] S.W. Allison, G.T. Gillies, A.J. Rondinone, M.R. Cates, Nanotechnology 14 (2003) 859

[6] M.A.R.C. Alencar, G.S. Maciel, C.B. de Araujo, Amitava Patra, Appl. Phys. Lett. 84 (2004) 4753.

[7] N. Salah, P.D. Sahare, S. Nawaz, S.P. Lochab, Radiat. Eff. Defects Solids 159 (2004) 321.

[8] A. Pandey, P.D. Sahare, J.S. Bakare, et al., J. Phys. D: Appl. Phys. 36 (2003) 2400

[9] N. Salah, P.D. Sahare, S.P. Lochab, Pratik Kumar, Radiat. Meas. 41 (2006) 40.

[10] T. Mimani, K.C. Patil, Mater. Phys. Mech. 4 (2001) 134.
[11] D.K. Williams, B. Bihari, B.M. Tissue, J.M. McHale, J. Phys.Chem. B 102 (1998) 916.

[12] K. Koch, W. Tuszynski, C.H. Tomaschko, H. Voit, Nucl. Instrum. Methods Phys. Res., Sect. B 146 (1998) 190.

[13] K. Koch, W. Tuszynski, H. Voit, Nucl. Instrum. Methods Phys. Res., Sect. B 209 (2003) 48.

[14] K. Schwartz, C. Trautmann, T. Steckenreiter, O. Geib, M. Kramer, Phy. Rev. B 58 (1998) 11232.

[15] V.A. Skuratov, A.E. Efimov, D.L. Zagorskii, Phys. Solid State 44 (2002) 171.

[16] Y. Song, C.H. Zhang, Z.G. Wang, Y.M. Sun, J.L. Duan, Z.M. Zhao, Nucl. Instrum. Methods Phys. Res., Sect. B 245 (2006) 210.

[17] K.R. Nagabhushana, B.N. Lakshminarasappa, G.T. Chandrappa, D. Haranath, Fouran Singh, Radiat. Eff. Defects Solids 162 (2007) 325.

[18] G. Hirata, N. Perea, M. Tejeda, J.A. Gonzalez-Ortega, J. McKittrick, Opt. Mater. 27 (2005) 1311

[19] J.F. Ziegler, Nucl. Instrum. Methods Phys. Res., Sect. B 219-220 (2004) 1027.

[20] B.D. Evans, J. Lumin. 60-61 (1994) 620.

[21] V.A. Skuratov, Kim Jong Gun, J. Stano, D.L. Zagorski, Nucl. Instrum. Methods Phys. Res., Sect. B 245 (2006) 194

[22] A. Al Ghamdi, P.D. Townsend, Nucl. Instrum. Methods Phys. Res., Sect. B 46 (1990) 133.

[23] C. Dalmasso, P. Iacconi, M. Beauvy, D. Lapraz, E. Balan, G. Calas, Radiat. Prot. Dosimetry 119 (2006) 222.

[24] R. Chen, S.W.S. McKeever, Theory of Thermoluminescence and Related Phenomena, World Scientific, Singapore, 1997.

[25] K.R. Nagabhushana, B.N. Lakshminarasappa, Fourn Singh, Radiat. Meas. 43 (2007) S651.

[26] A. Halperin, A.A. Braner, Phys. Rev. 117 (1960) 408. 